\title{
Parents Determination Factors Influencing Incomplete Basic Immunization For Infants In Sorong City, West Papua Province
}

\author{
Alva Cherry Mustamu ${ }^{1 a^{*}}$, Serly A. Markus ${ }^{2}$ \\ ${ }^{1}$ Poltekkes Kemenkes Sorong, Basuki Rahmat St, 11 Km, Sorong, Indonesia \\ 2 Sorong City Health Service, Sorong, Indonesia, alamat, kota, negara dan kode pos \\ a alvamustamu@gmail.com * \\ *corresponding author
}

\begin{tabular}{ll}
\hline Article History \\
\hline Submitted & $: 2$ Jan 2020 \\
Accepted & $: 30$ March 2020 \\
Revision & $: 20$ Feb 2020 \\
Published & $: 31$ April 2020
\end{tabular}

\section{Key word:}

Vaccine

Parental attitude

Infants

\begin{abstract}
The implementation of complete Indonesian basic immunization has decreased in the period of 2012 - 2015. West Papua is one of the provinces with the lowest immunization coverage, which is $57.1 \%$ and the city of Sorong is only $21.9 \%$.

This research is to investigate the determinant factors of parents in complete basic immunization of infants months in Sorong City, West Papua Province

This study was cross-sectional in design. The subjects consisted of a purposive sampling of 134 parents of children aged 1-5 years old, have incomplete basic immunization from immunization records and who visit 10 health center in Sorong City. Data were collected from parents using questionaires and immunization records. This study used logistic regression to analyze multivariate data. Simultaneously, mother's age, education level, occupational status, number of children, experience of having children, distance to the place of immunization, knowledge, family support, immunization officers and attitudes did not affect the incompleteness basic immunization (f count 1.768). Only the number of children $(\mathrm{t}=0.017)$ and immunization staff support $(\mathrm{t}$ $=0.044)$ which affected the incomplete immunization. sequentially, number of children $(\beta=0.003)$, immunization support staff $(\beta=0.004)$, distance to immunization site $(\beta=0.035)$ and attitudes $(\beta=0.027)$ which most contribute to incomplete immunization.
\end{abstract}

This is an openaccess article under the CC-BY-SAlicense. 


\section{Introduction}

Reduction of serious infections which are indicators of global public health success can be done by immunization. however, the implementation still found many obstacles which until now have not been found a solution because the scope of its implementation has not been comprehensive to all recipient subjects. The World Health Organization in 2017 estimates that around 19.4 million infants, children and toddlers throughout the world have not received complete basic immunization. About $60 \%$ of them live in low and middle income countries such as Asia, Africa and Ukraine including Indonesia. ${ }^{1}$

According to the Indonesian Ministry of Health's Center for Data and Information, the implementation of complete basic immunization for the 2012-2015 period did not reach the target and even decreased by $75 \%$ of the $80 \%$ target of the National Medium Term Development Plan. West Papua is the province with the lowest immunization coverage (57.1\%) and Sorong City only $21.9 \% .{ }^{2}$

The priority of immunization programs in each country varies, including Indonesia. Indonesia requires 3 doses of DPT-HB-Hib, 1 dose of Hepatitis B, BCG, measles and 4 doses of polio. ${ }^{2}$ Indonesia managed to carry out basic immunizations in all city districts such as measles and BCG which almost 95\%. But it did not occur in Hepatitis B, DPT, Polio and Tetanus immunizations in Papua and West Papua which were only under $80 \%$.

Although immunization is the biggest success in the health sector, there are still various obstacles to implementation. ${ }^{3}$ These problems include lack of access to health facilities due to poverty and ignorance (McHale P, Keenan A, Ghebrehewet S, 2015) and controversial ethics such as regulation, development, religion and beliefs, research and testing, informed consent and access gaps). Indonesia also has the same problem that is exacerbated by other problems such as differences in recording, validity, completeness and inaccuracies in the results of interviews and data between the center and the regions. ${ }^{2}$

These obstacles cause 2-3 million infant deaths in Indonesia each year. ${ }^{4}$ Even though the implementation of immunization in Indonesia is protected by law and the government is very active in carrying out it, but still encounters obstacles when implemented. Therefore, looking for causes for planning solutions must be done immediately.

This epidemiological study can help provide advice on selecting vaccines to be included in public health programs, identify target pathogens and disease-causing transmission pathways, disease burden, design disease control, determine appropriate strategies, monitor performance indicators, eradicate, monitor strategies, measure progress and the impact of the vaccination strategy.

\section{Material and method}

This study uses a cross sectional approach to analyze the factors that influence incomplete basic immunization for infants in Sorong City, West Papua Province. This study was conducted in 10 health centers in the city of Sorong is Malawei, Remu, Klasaman, Cape cassowary, doom, Malanu, Sorong West, East Sorong, Malaisimsa, Sorong City from October to November 2018.

The subjects consisted of a purposive sampling of 134 parents of children aged 
1-5 years old, have incomplete basic immunization from immunization records and who visit 10 health center in Sorong City and willingly become respondents.

The research instrument was a questionnaire used to measure Sociodemographics and economic Characteristics of participants for the behavioral determinants survey consisting of maternal age, parental education level, parental employment status, number of children, experience of having children, distance to the place of immunization, knowledge, family support, immunization officers and attitudes. Instrument for measuring complete basic immunization for infants was immunization record in health centre. immunization record is record of infants condition that showed history of immunization contains 3 doses of DPT-HB-Hib, 1 dose of Hepatitis B, BCG, measles and 4 doses of polio. Validity and reliability by Winarni (Sandra, 2010).

The Ethics Committee of the Health Polytechnic of health ministry Sorong, has provided recommendations for conducting research with number: DM.03.05/6/101/2018. Before the conduct of the field work, the researchers sought permission from each administrator at all levels. Each study participant was asked to participate in the study after explaining the aim of the study and after assuring confidentiality of personal information using code numbers instead of names.

The quantitative data were cleaned and entered into computer using SPSS version 17. Univarate analysis was used to describe the findings. Logistic regression analysis was used to determine the relationship and identify the most important factors in incomplete basic immunization status for infants.

\section{Result and discussion}

There was a 100\% response rate, of which, the large majority of them 128 (95.5\%) were in the less 35 years age group. A total of 127 (94.8\%) the study participants have high education. Half of the study participants were unemployed 75 (54.03\%). Total 78 $(58,2 \%)$ the study participants have had only had children. Most of them have less than 2 children in their home 128 (95.5\%). Most participants have male children 80 $(59,7 \%)$. Most of them have high level of knowledge about immunization 92 (68.7\%) and are supported by families 75 (56\%) but were not supported by immunization officers to immunize their children 69 (51.5\%) even though access to the immunization site is very close $100(74.6 \%)$. Therefore, respondents have a negative attitude towards immunization 100 (74.6\%) (Table 1)

Table 1. Socio-Demographics and Economic Participants Characteristics for The Behavioral Determinants Survey, 2018, Sorong

\begin{tabular}{lcc}
\hline \multicolumn{1}{c}{ Variable } & $\begin{array}{c}\text { Number } \\
(\mathbf{n}-\mathbf{1 3 4 )}\end{array}$ & $\%$ \\
Mother's Age (years) & & \\
$<35$ & 128 & 95.5 \\
$>35$ & 6 & 4.5 \\
Education levels & & \\
Primary & 7 & 5.2 \\
High & 127 & 94.8 \\
\hline
\end{tabular}

Alva Cherry Mustamu et.al (Parents Determination Factors Influencing Incomplete) 


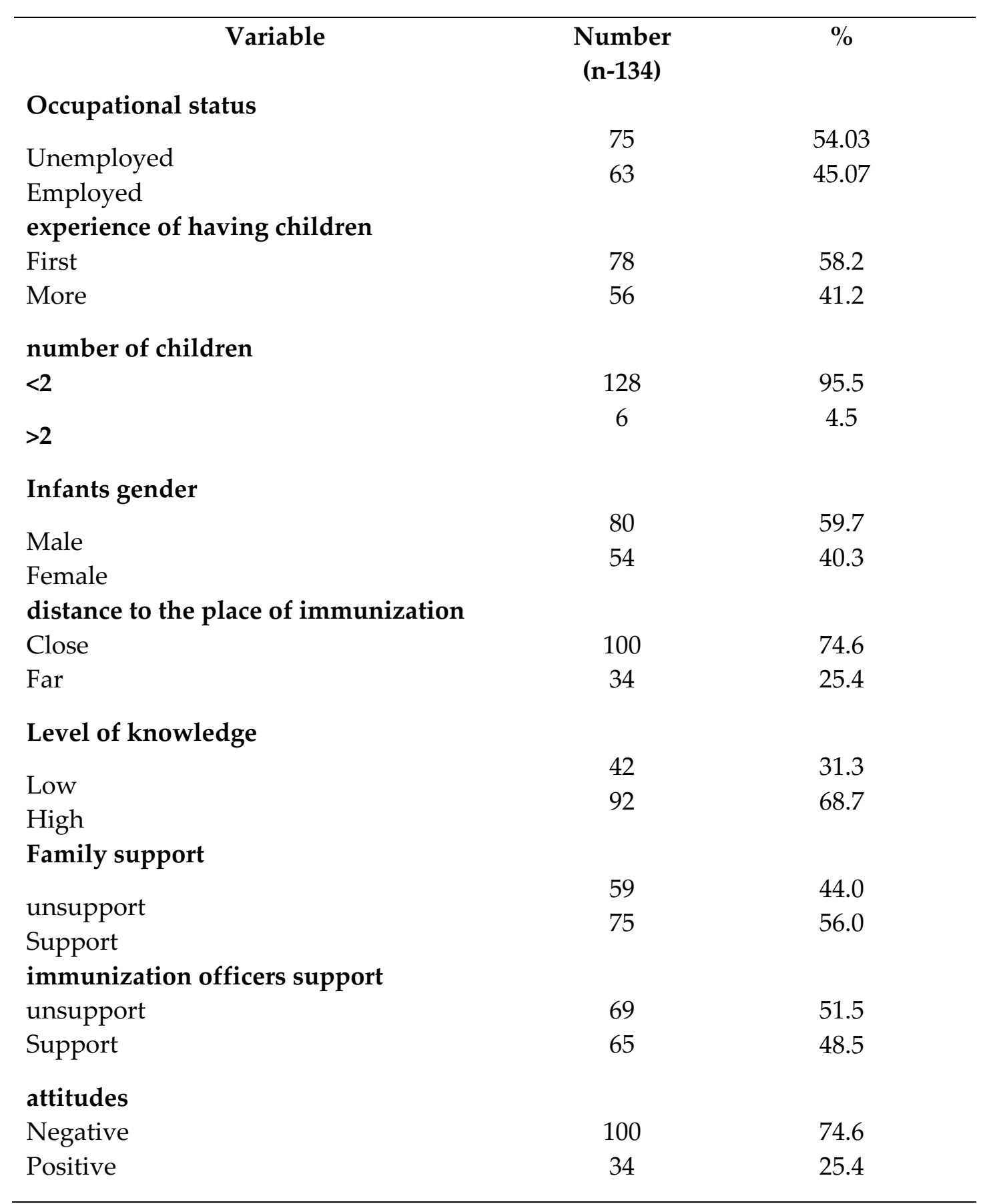

The factors that most influence the incompleteness of basic immunization status for infants in Sorong City during 2018 are presented in table 2. In the multivariate analysis, simultaneously mother's age, occupational status, number of children, experience of having children, distance to the place of immunization, level of knowledge dan education,, family support, immunization officers and attitudes did not affect the incompleteness basic immunization (f count 1.768). Only the number of children $(t=$ $0.017)$ and immunization staff support $(t=0.044)$ which affected the incomplete immunization. sequentially, number of children $(\beta=0.003)$, immunization support staff $(\beta=0.004)$, distance to immunization site $(\beta=0.035)$ and attitudes $(\beta=0.027)$ 
which contribute to incomplete immunization.

Tabel 2. Multivariable Logistic Regression Analysis of Factors Involved In The Incomplete Immunization.

\begin{tabular}{lcccc}
\hline \multicolumn{1}{c}{ Variabel } & F & $t$ & Beta & p-value \\
\hline Mother's Age (years) & 1.768 & 1.458 & 0.127 & 0.147 \\
Education levels & & 1.028 & 0.090 & 0.306 \\
Occupational status & 1.337 & 0.114 & 0.184 \\
number of children & 0.017 & 0.003 & 0.986 \\
experience of having children & 0.824 & 0.295 & 0.412 \\
distance to the place of & 0.264 & 0.027 & 0.793 \\
immunization & & & \\
Level of knowledge & 1.352 & 0.129 & 0.179 \\
Family support & 2.085 & 0.208 & 0.039 \\
immunization officers support & 0.044 & 0.004 & 0.965 \\
attitudes & 0.364 & 0.035 & 0.717 \\
\hline According & & & \\
\hline
\end{tabular}

According to the Indonesian Ministry of Health's Center for Data and Information, the implementation of complete basic immunization for the 2012-2015 period did not reach the target and even decreased by $75 \%$ of the $80 \%$ target of the National Medium Term Development Plan. West Papua is the province with the lowest immunization coverage $(57.1 \%)$ and Sorong City only $21.9 \%$. The main reason for vaccine uptake among HCWs, as supported by other studies, is that vaccination protects family members, friends and patients from being infected. ${ }^{5-7}$

The demographics of families are changing, and with that, the philosophical underpinnings of relationships are also changing. We found that, Only the number of children and immunization staff support which affected the incomplete immunization. Demo and Acock (1996) found that family processes are more important than family composition. ${ }^{8}$ O'Connor et al. (2001) show that the adjustment of children in family size is tantamount to the family structure. Demo and Acock (1996) 
further explained that the measure of family relations explained the largest proportion of variance in the welfare of adolescents.

Many parents worry about vaccine safety because the controversy regarding the use of mercury in vaccines has been around since 1999. But after that, the American Academy of Pediatrics and US Public Health Services recommended that children's immunization vaccines be made without preservatives. in addition, it was strengthened by immunization officers providing counseling to parents about vaccine safety.

In a study of 3,924 older people, the most common reasons that lead to incomplete immunization is a concern about the safety and side effects of vaccines, especially in varicella and MMR immunization. Like other health care fields, decision making based on more information influencing immunization decision making in recent years. This decision is a decision based on relevant knowledge, because it reflects the values of decision makers. Information from health workers and immunization officers can change the minds of parents. Accessing the right sources of information by parents directed by health workers and giving them time to study these resources is very helpful in increasing their knowledge.

Research shows that parents who rarely access health services can make them vulnerable to invalid information. Finding information about immunizations from online sources, especially through search engines and on social media causes confusion in the elderly [35]. Another explanation that might underlie parents who refuse vaccination is the lack of knowledge and distrust of information provided by immunization officers. More research is needed to find out what information parents need to make decisions about vaccinating children.

Planning behavior theory is one theory that has been successfully applied to improve immunization implementation decisions because it includes the process of consideration by decision makers; information processing available by thinking of the consequences of decisions and weighing pros and cons. Vaccination decisions are included in health decisions that require consideration by parents. Deliberations between husband and wife can increase positive attitudes in the implementation of immunization. More research is needed on the reasons for consideration of parents who receive vaccinations because this will result in a more stable attitude towards child immunization.

Availability and access to immunization services tends to be worse in the sub-region of West Papua where the population is less dense or mountainous areas. Although the problem is not related to immunization facilities, this problem seems to be related to immunization status. This finding was also seen in other studies. For example, a study in Bangladesh found that women who reported at the nearest health facility $(<1 \mathrm{~km})$ are more likely to immunize their children are fully.

Another study, in India, found a positive relationship between the existence of a health center within $2 \mathrm{~km}$ of the village. urban slums and immunization status of children. Further studies are needed to understand the perceptions of parents in the city of Sorong about the distance to immunization and other health services.

Seasonal migration in homes anchored to and from urban shocks is quite common and affects immunization coverage. Families sailing to become fishermen for better economic opportunities directly affect the use of health services and immunization. the problem encountered was that they lost time to immunize, children were left by caregivers, or parents forgot immunization records. 
An integrated tracking and reporting system must be implemented so that the baby gets complete basic immunization from sites other than the designated site. This system can track these children for the next vaccination. This study has important implications in the development of policies and programs for the implementation of complete basic immunization in infants. Vaccination coverage can be increased in remote areas by increasing access and reducing travel time to health facilities. hospitals and health centers that assist in the delivery process can have integrated data with health facilities in the patient's domicile. so, health workers can carry out immunizations to the patient's home.

Additional immunization activities can also contribute to increasing measles immunization coverage in infancy and reducing inequality. If necessary, outreach programs and additional immunization activities should be considered to increase coverage in remote areas. In addition, a new vaccine strategy is needed for the most difficult to reach children in West Papua and other parts of West Papua

\section{Conclusion}

Affordability to immunization facilities and support from immunization officers greatly influences the attitudes of parents in carrying out immunizations. motivation in carrying out immunization is very dependent on the right information and the comfort of the subjects receiving immunization services. in addition, integrated information between health facilities from the birth process to the age of 12 months is very helpful in meeting the targets of complete basic immunization.

\section{Reference}

1. No

Title. http://www.unicef.org/immunization/files/SOWVI_full_report_english_LR 1.pdf.

2. P.U.S.D.A.T.I.N. Situasi dan analisis imunisasi. http:/ / www.pusdatin.kemkes.go.id/resources/download/pusdatin/infodati $\mathrm{n} /$ infodatin-imunisasi.pdf.

3. Prevention $C$ for DC and. Thimerosal in vaccines: a joint statement of the American Academy of Pediatrics and the Public Health Service. Morb Mortal Wkly Rep. 1999;48(26):563-565.

4. World Health Statistics, 2015) maternal mortality rate. http:/ / apps.who.int/iris/bitstream/handle/10665/170250/9789240694439_en g.pdf;jsessionid=F3DF210FE92867C2B1C9F25B482DF7E6? sequence=1.

5. Torre G, Semyonov L, Mannocci A. Knowledge, Attitude, and Behaviour of Public Health Doctors towards Pandemic Influenza Compared to the General Population in Italy. Scand J Public Health.;40:69-75

6. Prematunge C, Corace K, McCarthy A. Factors influencing pandemic influenza vaccination of health care workers: a systematic review. Vaccine. 30:4733-4743.

7. Mir O, Adam J, Gaillard R. Vaccination coverage among medical residents in Paris, France.

8. Demo DH, Acock AC. Family structure, family process, and adolescent wellbeing. J Res Adolesc. 6(4):457-488. 